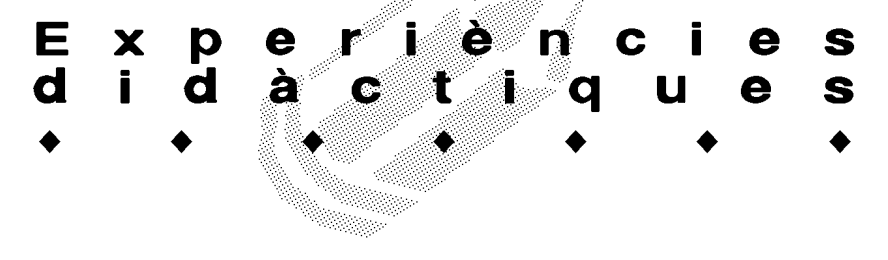

\title{
LA POESIA AL CICLE SUPERIOR DE L'ESCOLA PRIMÀRIA
}

\author{
Isabel Castilleja Conejo. Mestra del CEIP de Pràctiques. Tarragona
}

\section{Poesia a l'escola?}

Els lectors d'una certa edat potser recordaran que a l'escola d'abans feien aprendre les poesies de memòria, com una llicó més, amb uns aspectes molt concrets que adoctrinaven sobre un tema o un altre. Encara recordo molt algunes poesies referents a la religió; en llengua castellana, per descomptat. L'aprenentatge d'aquells poemes no era un joc. Era una obligació i força feixuga, de vegades.

És per això que avui dia hem de fer arribar la poesia d'una altra manera i amb una altra mena de versos. Actualment no es tracta d'alliçonar, sinó d'obrir els ulls a la sensibilitat, i dir les coses de cada dia d'una manera bella i diferent. Per convertir la vida en un joc, alegre o dolorós. Perquè tot estimant les paraules sàpiguen estimar les persones.

Encara que el títol d'aquest treball només fa referència al cicle superior de primària, no significa que la poesia es treballi esclusivament en aquesta etapa. Es podria dir que en aquest cicle -per l'edat dels alumnespotser és el moment oportú per arribar als nens d'una manera diferent; i això ens dóna un ventall molt ric de possibilitats. De fet, tots sabem que des de ben petits la poesia és una constant en la formació humanística $\mathrm{i}$ sensorial dels nostres alumnes.

No és agosarat dir que el llenguatge poètic gaire bé és present a tota la primària. A l'educació infantil canten cançons i reciten petits poemes que són la delícia del professor i dels pares, que reconeixen entusiasmats el treball memorístic dels alumnes i fills. Al cicle inicial ja són capaços de crear -per ells mateixos- petits rodolins, que és un primer pas en el camí del poeta. I rodolí a rodolí, els més espavilats formen poesies, que acaben convertint-se en auques la mar de simpàtiques. És ara quan comencen a adonar-se que això funciona, i que aixòté música. És aquí quan l'educador pot aprofitar-ho per deixar caure les paraules: versos, rima i estrofes, i que a poc a poc les incorporin en el seu vocabulari. Aquest treball té una continuïtat en el cicle mitjà.

Es podria dir, doncs, que el llenguatge poètic és una tipologia de textos que es treballa a l'escola primària. No és un llenguatge fàcil, i malgrat tot, els nens el coneixen. De vegades s'aprofundeix massa en el seu estudi; d'altres, no se li dóna la importància que té en el desenvolupament de la personalitat del nen.

L'edat d'onze i dotze anys, la dels alumnes del cicle superior, és una edat que comença a ser complicada per a ells mateixos: se'ls obre tot un món de sensibilitats, de comprensió incompresa, de sentiments vers tot, i comencen a sentir la necessitat de expressar-los d'alguna manera.

\section{Objectius de la poesia a l'escola}

La poesia pot ser un camí com un altre per aprendre la teoria del llenguatge en totes les seves variants, així com una manera que tenen els nens per exterioritzar el seu món interior, ja sigui llegint-la, interpretant-la o creantla.

Amb la poesia es poden potenciar objectius molt concrets:

- Agilitzar la imaginació i la creativitat dels alumnes.

- Aprendre a llegir, a interpretar o dramatittzar la poesia.

- Gaudir de la seva lectura.

- Reconèixer els elements del llenguatge poètic.

- Utilitzar en la poesia altres recursos del llenguatge com poden ser, la metàfora i la imatge.

- Conèixer els nostres poetes.

- En definitiva: crear poesia, crear il-lusions, estimar la poesia.

\section{Metodologia d'aprenentatge}

Per arribar a aconseguir tots aquests objectius s'han de seguir uns passos. Es començarà llegint poesia. La lectura de la poesia sembla difícil, i ho sembla perquè demana un temps determinat per fer-ho. Si llegeixes de pressa, el sentit de les paraules se t'escapen, i sobretot és necessari respectar els signes de puntuació que l'autor ha col-locat específicament per donar-hi el sentit que ell pretén.

Així doncs, cal llegir la poesia en veu alta una i altra vegada, i escoltar-la de la veu d'un altre que la recita, tot intentant trobar la musicalitat del missatge.

Cal també aturar-se en aquelles paraules que no s'acaben d'entendre. És el moment de buscar sinònims o antònims que ajudin en la seva comprensió, o d'explicar 


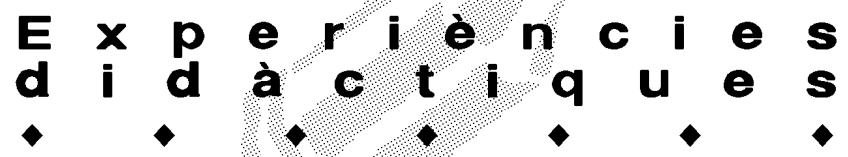

les metàfores que hi hagi.

Quan la poesia ja l'entenen, i els agrada, és quan, amb el procés de llegir i d'escoltar, arribaran a memoritzar-la, ja sigui per estrofes o bé sencera.

És maco no encasellar-se en un o dos autors, sinó donar a conèixer tot un ventall de poetes, per tal d'arribar a tots, ja que hem de tenir present que cadascú té una sensibilitat pròpia davant els temes i les coses. Mentre a un nen/a li agrada un tipus de poesia més infantil, a un altre pot agradar-li un tema més profund o compromès

\section{SI ET QUEDES AMB MI}

Més lluny de les muntanyes jo vull trobar un racó per viure sense pressa i ser l'ombra del teu cos.

Si et quedes, ah!, si et quedes amb mi.

No et puc donar riquesa, no puc donar-t'ho tot.

puc ser el teu llarg viatge, puc ser la llum del sol.

Si et quedes, ah!, si et quedes amb mi.

Quan estiguis cansada jo et donaré repòs.

Quan res no vulguis veure t'ompliré els ulls de flors.

De dia quan despertis vull estar al teu cantó, vull tenir les mans buides per prendre el teu amor.

Quan se't tanquin les portes jo t'obriré el balcó, quan creguis que estàs sola podràs cridar el meu nom.

Si et quedes, ah!, si et quedes amb mi.

No vull guanyar cap guerra, no vull ser el teu heroi, no vull fer cap promesa, no vull entendre el món.

Despinta les banderes i fes-ne un gran Ilençol, per sobre les fronteres podràs sentir-me a prop.

Més lluny de les muntanyes hi haurà d'haver algun lloc per viure sense pressa i ser l'ombra del teu cos.

$\mathrm{Si}$ et quedes, ah!, si et quedes amb mi.

Gerard Quintana (Sopa de Cabra) amb la societat; això després es reflectirà en les seves creacions espontànies.

S'ha de tenir clar que la poesia és pròxima a altres tipus d'expressió com la narració, la descripció i el diàleg. Únicament es diferencia d'elles en l'aspecte formal de l'expressió, ja que s'han de respectar els versos, que poden rimar o no, i això suposa una pauta diferent. L'important és que les poesies tinguin sentit, que al llegir-les tinguin música, i sobretot que siguin fruit de la creativitat de l'alumne/a.

Quan els nens estan sensibilitzats, és quan volen experimentar per ells mateixos, quan volen jugar a fer de poetes. En aquest moment és quan seran capaços d'escriure les seves pròpies poesies, emocions, vivències, experiències...

$\mathrm{Hi}$ ha nens/es que ràpidament saben situar-se en qualsevol tema, però altres no tenen aquesta facilitat; per tant, és convenient, ajudar-los. Una forma de fer-ho pot ser aquesta:

Un dia podem escriure quatre paraules-clau a la pissarra, més o menys relacionades entre elles, i que a partir d'elles escriguin una poesia.

Un altre dia aprofitarem una experiència escolar (colònies, excursió, festa popular) per demanar-los que escriguin una poesia amb aquesta temàtica.

I un altre, un alumne, en forma de poema, formularà una sèrie de preguntes, a les quals un company haurà de respondre. És a dir, serà un poema fet en col.laboració. O simplement expressaran poèticament allò que els passa pel cap, o que senten, o que volen, segons la seva inspiració en aquell moment.

La cançó no és altra cosa que poesia musicada. Actualment molts grups musicals han incorporat al seu repertori poemes d'autors importants. Un cas interessant és el del grup "Sopa de cabra", que amb la cançó "Si et quedes amb mi" arriba molt a la joventut. Això els motiva per memoritzar-la. Així doncs, ens trobem davant una forma de treballar la capacitat memorística de l'infant. Fins i tot es pot fer un dictat musical, o es pot treballar l'atenció, ja que aquesta cançó canvia la música en funció del missatge amorós que conté.

\section{Altres recursos i estratègies}

$\mathrm{Hi}$ ha altres recursos per introduir la poesia. A més a més de treballar -la, memoritzar-la, fomentar l'atenció i la companyonia, és convenient que s'ho passin bé. És el cas d'aquest exercici:

- Amb tota la classe aixecada, el professor/a llegeix el primer vers.

- Un nen/a de la classe fa el gest relacionat amb el missatge del primer vers.

- Ho repeteix tota la classe, vers parlat i gest. 


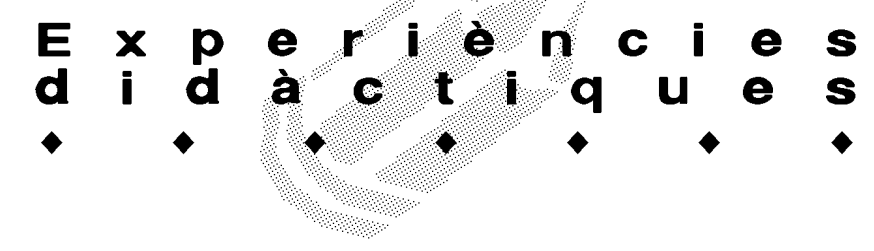

- Es continua amb el següent vers; un altre nen/a fa el gest corresponent.

- La classe ho repeteix, però començant des del primer vers.

- Se segueix així fins a acabar el poema (s'ha de procurar que no sigui excessivament llarg).

- Finalment, de tant repetir-lo, acaben sabent-se el poema. Per donar-li més emoció, es poden introduir variants com: repetir el text sense incloure-hi gestos. O es pot procedir a l'inrevés, reproduir els gestos sense paraules.

Amb aquest exercici, tan senzill com agradable, esl nens/es s'ho passen molt bé, perquè és una manera de divertir-se tot aprenent. I sense adonar-se'n faran un treball lingüístic que els permetrà conèixer un cert vocabulari i formes d'expressió diferents.

Per la complexitat del tema i dels horaris, sempre s'ha d'aprofitar la motivació dels alumnes. Així doncs, cal treballar la poesia segons la seva demanda, i descansar quan l'educador -basant-se en la seva experiència- ho cregui oportú. Així es pot donar pas a altres activitats que els ofereixin una millor forma d'expressió, ja que tots no arriben a introduir-se en el camp de la poesia amb la mateixa sensibilitat. Sensibilitat, per altra banda, que si no es recondueix bé, potser no esclatarà mai.

Una altra vessant que ofereix aquesta activitat és el recull de tots els treballs produïts, fent un llibre de poemes. Aquests poemes caldrà il-lustrar-los amb sanefes i dibuixos relacionats amb el tema; d'aquesta forma es pot crear un lligam interdisciplinari entre la llengua i l'expressió plàstica.

\section{A tall de conclusió}

Una frase d'un poeta txec en llengua alemanya, Rainer Maria Rilke, considerat un dels primers lírics del segle $X X$, té una frescor tan natural que recull tot allò que es pot dir de la poesia: La primavera és com un nen que sap poesies.

Quan la poesia ha estat una constant en l'aprenentatge dels alumnes de cicle superior, i de tant en tant, han jugat a ser poetes, o simplement han memoritzat una poesia, afegint-hi el gest i el mim, realment tenen un bagatge important i els treballs que sorgeixen són força creatius. En aquesta etapa de la seva vida ja saben fer, entendre i sentir la poesia. Molts d'ells reconeixen la musicalitat i saben incloure en els versos les seves sensacions. I ho fan de la manera més apropiada per aconseguir trasmetre el missatge que volen.

El tema poètic no és important. Tant fa escriure sobre el sol, la lluna, l'escola o l'amic. L'important no són les paraules emprades, sinó com s'utilitzen per tal

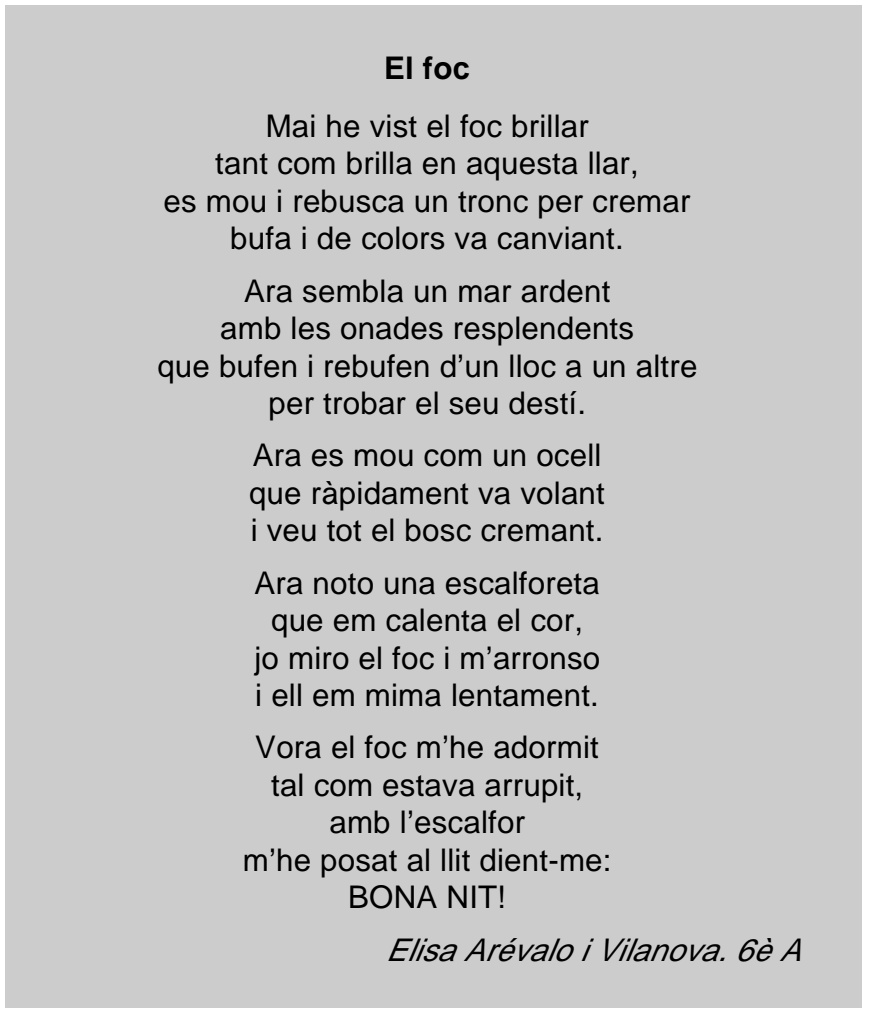

que diguin allò que els sentiments volen que diguin. Les primeres poesies sempre costen de fer. És tan difícil que sonin bé, que diguin alguna cosa important, que expressin tot allò que es té a dins. A poc a poc, a base de dominar els rodolins, les llegendes i les endevinalles, ells mateixos es llancen i s'introdueixen en els versos lliures, aprenent a escurçar-los i a allargar-los segons les seves necessitats.

El nostre suport com a educadors és important, els dóna seguretat i motivació per a continuar, sobretot quan veuen la seva creació exposada o publicada, com és el cas de les poesies de nens/es de 6è curs de primària. El resultat és sempre positiu, i qui sap, potser algú trobarà aquell cuquet que li donarà la llum que li faci descobrir que ha nascut per ser un gran poeta.

Realment, descobrir la poesia és una cosa viva, enriquidora i divertida. És arribar a un llenguatge ple de sensibilitat i d'imaginació, que pot donar lloc que els nostres joves entenguin la vida d'una manera constructiva. 